\title{
แțestiênc|a
}

\section{EMPREENDENDO PARA A VIDA: A EMPRESA ECOPUFF PARA ALÉM DE RESULTADOS FINANCEIROS}

\author{
ENTREPRENEURING FOR LIFE: THE ECOPUFF COMPANY BEYOND \\ FINANCIAL RESULTS
}

\author{
${ }^{1}$ Larissa Haddad Souza Vieira* \\ ${ }^{2}$ Raphael Magalhães Gomes Moreira \\ ${ }^{3}$ Stefany Sampaio Silveira \\ ${ }^{4}$ Diná Castiglioni Printini \\ ${ }^{5}$ Hugo Martins de Carvalho \\ ${ }^{6}$ Vinícius Quiuqui Manzoli \\ ${ }^{7}$ Lorena dos Santos Silva
}

\begin{abstract}
${ }^{1}$ Instituto Federal do Espírito Santo. E-mail: larissa.vieira@ifes.edu.br ${ }^{2}$ Instituto Federal do Espírito Santo. E-mail: raphael.moreira@ifes.edu.br ${ }^{3}$ Instituto Federal do Espírito Santo. E-mail: stefanysilveira.s@gmail.com ${ }^{4}$ Instituto Federal do Espírito Santo. E-mail: dina_castiglioni@hotmail.com ${ }^{5}$ Instituto Federal do Espírito Santo. E-mail: hugomartins.adm@gmail.com

${ }^{6}$ Instituto Federal do Espírito Santo. E-mail: viniquiuqui@gmail.com

${ }^{7}$ Instituto Federal do Espírito Santo. E-mail: lorenadossantos22@gmail.com

*Autor de correspondência
\end{abstract}

Artigo submetido em 25/03/2020, aceito em 21/12/2020 e publicado em 27/05/2021.

Resumo: O artigo apresenta os resultados do Programa Miniempresa realizado no Instituto Federal do Espírito Santo (Ifes) campus Itapina, segundo a percepção dos alunos participantes e os dados administrativos da empresa dele derivada, a EcoPuff. O Miniempresa é um programa de sensibilização ao empreendedorismo, baseado em conceitos de economia, gestão e negócios, voltado a alunos do Ensino Médio, idealizado e orientado pela Junior Achievement em âmbito mundial, objetivando formar jovens para o mercado de trabalho formal e disseminar a cultura empreendedora, a partir da formação e desenvolvimento de uma empresa estudantil. Partiu-se do questionamento: o Programa Miniempresa, como instrumento de educação empreendedora, contribuiu para a formação dos jovens participantes, segundo sua própria percepção? Objetivou-se investigar a percepção dos participantes sobre o Miniempresa, identificando as contribuições do programa para sua formação, bem como resultados administrativos da empresa Ecopuff. A pesquisa é qualitativa, caracterizando-se como estudo de caso. A coleta de dados foi realizada por meio de análise documental em relatórios da empresa e por questionário aplicado aos empreendedores da Miniempresa do Ifes campus Itapina. Conclui-se que o programa estimula o empreendedorismo, gerando oportunidades a estudantes do Ensino Médio de ingressarem no mercado de trabalho mais preparados, contribuindo com o desenvolvimento pessoal e do perfil empreendedor desses jovens; para além dos parcos resultados financeiros e de produtividade empresarial, foi instrumento de aprendizado para sua vida.

Palavras-chave: Empreendedorismo; educação; sustentabilidade; voluntariado. 


\begin{abstract}
The article presents the results of the Miniempresa Program held in Federal Institute of Espírito Santo (Ifes) campus Itapina, according to the perception of the participating students and the administrative data of the company derived from it, EcoPuff. Miniempresa is a program to raise awareness of entrepreneurship, based on economics, management and business concepts, destined to high school students, designed and guided by Junior Achievement worldwide, aiming to train young people for the formal job market and disseminate culture entrepreneurial, from the formation and development of a student company. It started with the question: did the Miniempresa Program, as an instrument of entrepreneurial education, contribute to the formation of young participants, according to their own perception? The objective was to investigate the participants' perception of the Miniempresa, identifying the program's contributions to its formation and suggestions for improvements for future editions, as well as administrative results of the company Ecopuff. The research is qualitative, characterized as a case study. Data collection was carried out by document analysis in company reports, and by questionnaire applied to the entrepreneurs of Miniempresa in Ifes campus Itapina. It is concluded that the program encourages entrepreneurship, generating opportunities for high school students to enter the job market more prepared, contributing to the personal development and entrepreneurial profile of these young people; in addition to the meager financial results and business productivity, it was a learning tool for their life.
\end{abstract}

Keywords: Entrepreneurship; education; sustainability; volunteering.

\section{INTRODUÇÃO}

Com o passar dos séculos e o avanço da globalização em todo o mundo, ocorreu um estímulo ao empreendedorismo, através da geração de ideias inovadoras e da criação de tecnologias, promovendo o desenvolvimento da sociedade. Os empreendedores, isto é, os agentes do empreendedorismo, têm eliminado barreiras comerciais e culturais e encurtado distâncias, "renovando os conceitos econômicos, criando novas relações de trabalho e novos empregos, quebrando paradigmas e gerando riqueza para a sociedade" (DORNELAS, 2001, p. 21).

O empreendedor possui o potencial para modificar o estilo de vida da população, inovando, criando ou recriando coisas e comportamentos, por ter um perfil executor e de antecipação aos fatos. Dessa forma, sua ação implica na formação de uma cultura do empreendedorismo a partir de hábitos, costumes, práticas e valores, o que influencia diretamente sobre o desenvolvimento local (AMORIM, 2018).

Para Dolabela (2003) o ambiente desenvolve o empreendedor e os fatores que facilitam o empreendedorismo em uma comunidade são: ambiente favorável ao desenvolvimento de novos negócios, com políticas e programas adequados à realidade do empreendedor; disseminação de cultura empreendedora; apoio ao empreendedor nos aspectos cultural, educacional e de disponibilidade de recursos financeiros e tecnológicos; acesso a inovação, e outros.

A escola é uma das responsáveis por veicular grande parte da cultura da sociedade em que os estudantes estão inseridos, incluindo a cultura empreendedora. Frente a diversas oportunidades e avanços tecnológicos, a atual geração de estudantes tem se perguntado qual caminho profissional seguir, e como resposta a esses anseios pode ter no empreendedorismo uma forma diferente de ver o mundo e mudar a realidade onde está inserida.

Por meio de capacitações e programas educativos é possível contribuir para a transformação de estudantes e lhes conceder oportunidades de aperfeiçoamento profissional e pessoal, desenvolvendo seu perfil empreendedor. Segundo Dolabela (2003), a prática do empreendedorismo vem ocupando um espaço de grande relevância na educação básica brasileira, mas não é a realidade da maioria das instituições de ensino. Souza et. al. (2004) defendem o desenvolvimento do perfil empreendedor no 
contexto escolar, capacitando os estudantes para que criem e implementem novos planos de vida para si mesmos, de forma mais criativa e protagonista.

Desta forma, entende-se que o ensino deve utilizar metodologias e ferramentas que levem o aluno ao contato com a realidade prática do empreendedorismo. Segundo Lopes (2010), a Educação Empreendedora envolve todo o contexto do aprendizado, desde os conhecimentos, habilidades, atitudes e qualidades internas. Essa educação enfatiza o uso intenso de metodologias de ensino que permitam aprender fazendo e se caracteriza por isso, pois o indivíduo se defronta com eventos críticos que o forçam a pensar de maneira diferente, buscando saídas e alternativas, ou seja, aprendendo com a experiência, com o processo.

Nesse ínterim, se reitera como a inserção do empreendedorismo na educação pode desenvolver a cultura empreendedora na sociedade brasileira, evidenciando experiências que proponham a interação entre o contexto escolar e as realidades e vivências empreendedoras.

Diante do exposto, observou-se por parte da Incubadora do Instituto Federal do Espírito Santo (Ifes) campus Itapina a necessidade de ações que não visassem apenas ações de Extensão, voltadas a empreendedores externos ao Campus, mas a proposição também de ações de Ensino para a educação básica, destinadas aos cursos Técnicos Integrados ao Ensino Médio do campus, para criar um microclima empreendedor também na próxima geração empreendedora. A ferramenta escolhida foi o Programa Miniempresa, a partir da parceria com a Junior Achievement Espírito Santo (JAES).

\section{O Programa Miniempresa} proporciona a estudantes do $2^{\circ}$ ano do Ensino Médio a experiência prática da gestão de negócios, desde a organização à operação de uma empresa. É desenvolvido a partir de 18 encontros semanais, com duração de 3h30min cada, em horário distinto ao horário de aulas. Os estudantes aprendem conceitos de livre iniciativa, mercado, comercialização e produção. É acompanhado por profissionais voluntários das áreas de marketing, finanças, recursos humanos e produção. Os fundamentos são explicados através do método AprenderFazendo, em que cada participante se converte em um miniempresário (JUNIOR ACHIEVEMENT, s/d).

No Programa Miniempresa são desenvolvidas práticas empreendedoras junto a estudantes da educação básica, por meio da criação e administração de uma empresa. No Ifes campus Itapina, a empresa constituída pelos estudantes foi a EcoPuff, destinada à produção e venda de pufes decorativos elaborados a partir de resíduos como garrafas pet e papelão.

Este artigo objetiva investigar a percepção dos alunos participantes sobre o Miniempresa, identificando as contribuições do programa para sua formação, bem como resultados administrativos da empresa Ecopuff.

\section{CONSIDERAÇÕES METODOLÓGICAS}

Este estudo, de natureza qualitativa, possui característica descritiva apoiada em metodologia de Estudo de Caso. Segundo Yin (2015), o estudo de caso é uma pesquisa empírica que investiga um fenômeno contemporâneo, dentro de um contexto de vida real, evidenciando a relevância desse fenômeno em determinado contexto.

A coleta de dados referentes aos resultados da EcoPuff foi realizada por meio de análise documental em relatórios da empresa, dos setores de Recursos Humanos, Produção e Financeiro, elaborados ao final da implementação do Programa.

A percepção dos participantes sobre o Programa se apoiou na pesquisa de campo, feita por meio de aplicação de questionários junto aos participantes (achievers) do Programa Miniempresa no 
Ifes campus Itapina, localizado na cidade de Colatina, Espírito Santo, ao final do período de execução do Programa (agosto de 2018). Os questionários foram respondidos por 15 estudantes, dentre os 19 que concluíram o Programa (79\% do total), sendo 10 meninos e 5 meninas, com idades de 16 (40\% dos respondentes), 17 (53\%) e 18 anos (7\%). Todos os componentes das Diretorias (5) responderam ao questionário.

A análise de dados foi feita com base em análise de frequências e de médias estatísticas, estas últimas aplicadas a percepções dos alunos, mensuradas a partir de escala tipo Likert, com 5 categorias. Esse tipo de escala foi proposta e explicada por Rensis Likert, em 1932, sendo frequentemente utilizada nos dias atuais, em especial em pesquisas no campo das ciências sociais aplicadas. Utiliza a especificação de pontos com designações qualitativas, geralmente em quantidade ímpar, buscando valoração negativa, neutra e positiva para o fenômeno que deseja avaliar.

\section{ECOPUFF: ORGANIZAÇÃO E RESULTADOS EMPRESARIAIS}

As atividades do Programa Miniempresa no Ifes campus Itapina foram iniciadas no Instituto em março de 2018 e finalizadas em agosto do mesmo ano. Foram desenvolvidas durante 18 jornadas nas dependências do Campus Itapina, simulando a atividade empresarial. Ao início da implementação do Programa, foi definido pelos estudantes participantes, em um processo de escolha entre vários produtos propostos, que a empresa a ser constituída seria destinada à produção e venda de pufes decorativos, elaborados a partir de resíduos domésticos como garrafas pet e papelão.

Após votação de vários nomes sugeridos, a empresa foi denominada EcoPuff, evidenciando elementos de sua missão, visão e valores organizacionais, tais como a sustentabilidade ambiental, a destinação de resíduos, a qualidade estética e material de produtos em decoração, a praticidade e durabilidade de seu produto.

Para possibilitar o melhor desenvolvimento das ações propostas, a organização de pessoal e de setores foi feita na Ecopuff conforme organograma apresentado na Figura 1.

Figura 1 - Organograma da Ecopuff

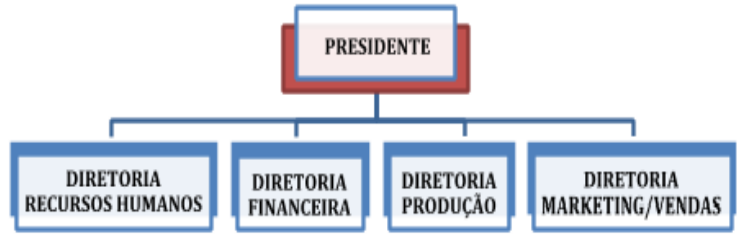

Fonte: Elaboração própria, a partir de relatórios da EcoPuff

As atribuições de cada Diretor especificado na Figura 1 estão relacionadas às seguintes funções administrativas: Recursos Humanos ou Gestão de Pessoas, Financeiro, Produção, e Marketing e Vendas. A Diretoria de RH ocupou-se da organização e motivação da equipe, controle de frequências, visando à manutenção das atividades propostas, e respectiva remuneração prevista pelas jornadas de produção de pufes.

Iniciada com a participação de 34 estudantes dos segundos anos dos cursos Técnicos em Agropecuária e em Zootecnia Integrados ao Ensino Médio, a Ecopuff teve evasão de 15, isto é, 44\% dos alunos, concluindo as atividades com 19 estudantes. Esses alunos pararam de frequentar antes mesmo de ser iniciada a produção de pufes ( $6^{\circ}$ encontro), não tendo participado das atividades do Programa como um todo. Seu desligamento se deve especialmente à incompatibilidade entre suas expectativas quanto ao projeto e a realidade experimentada, que se mostrou mais complexa e trabalhosa que o esperado. Um estudante evadiu após o início do processo produtivo, pois foi transferido de escola.

O gráfico 1 apresenta a progressão de frequência dos participantes da Miniempresa, a partir da sexta semana de 
encontros, quando os colaboradores da empresa Ecopuff passaram a ser remunerados por sua participação. Estão contabilizados apenas os estudantes que tiveram presença nos encontros de produção, excetuando-se aqueles evadidos ao início da implementação do Programa.

\section{Gráfico 1 - Progressão de frequência dos} participantes da Miniempresa

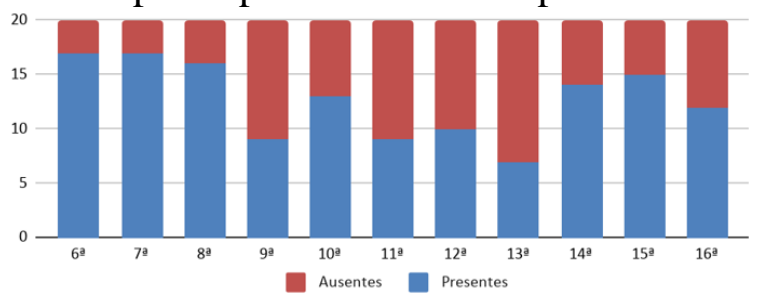

Fonte: Elaboração própria, a partir de relatórios da EcoPuff

O resultado apresentado no Gráfico 1 aponta para as dificuldades enfrentadas pelos estudantes participantes diante do excesso de atividades escolares, dado o volume de ações curriculares de seus cursos, que acontecem em turno integral, o que é evidenciado pelo alto índice de faltas nos encontros realizados ao final do semestre letivo ( $9^{\mathrm{a}}$ a $13^{\mathrm{a}}$ semana), quando tiveram mais atividades avaliativas relacionadas aos seus cursos regulares.

As faltas coletivas computadas em períodos de provas e demais avaliações semestrais poderiam ter impactado diretamente sobre a produtividade da EcoPuff, pois a força de trabalho para a produção de pufes relaciona-se ao número de participantes presentes. Contudo, o Gráfico 2 demonstra que não houve essa relação direta, pois o período em que houve mais faltas foi também o que mais teve unidades produzidas de pufes.

Gráfico 2 - Produção de Pufes por jornada

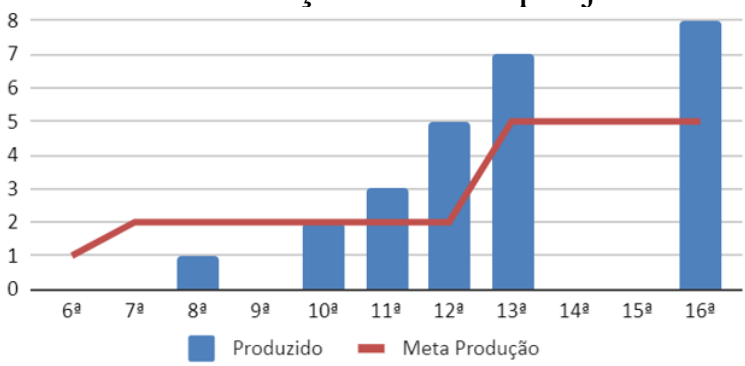

Fonte: Elaboração própria, a partir de relatórios da EcoPuff

De acordo com o Gráfico 2, a produtividade da Ecopuff foi crescente, mesmo com poucos participantes presentes. Esse resultado se deve ao estímulo dado pelos voluntários da equipe coordenadora do Programa aos participantes, demonstrando a necessidade de aumento no número de pufes produzidos, com o objetivo de atingir às metas previamente definidas, atender às demandas e pedidos e, consequentemente, ter lucratividade.

O período sem produção $\left(14^{\mathrm{a}}\right.$ e $15^{\mathrm{a}}$ semanas) se explica pela dificuldade em obter matérias-primas apropriadas à produção. $\mathrm{O}$ aproveitamento de garrafas pet recicláveis para a produção de pufes ecológicos limitou esse processo, pois a variedade de modelos de embalagens influenciava na qualidade e estabilidade almejada para o produto, dificultando a seleção e separação de materiais.

Somado a isso, mesmo os estudantes tendo implantado paralelamente um projeto de coleta de garrafas pet no refeitório do campus, visando atender ao Programa Miniempresa, a oferta de recicláveis para matéria-prima produzida no campus e em seu entorno, como esperado inicialmente, não foi suficiente para atender a demanda de produção, havendo atrasos no planejamento de produção e disponibilização dos pufes ao setor comercial, sendo necessário criar alternativas à captação de matérias-primas. Dessa forma, os participantes precisaram trazer garrafas pet de suas residências, para compor a produção dos pufes.

Diante das dificuldades com matéria-prima, a empresa passou a maioria das jornadas com um excedente de mão-deobra ocioso, o que também aumentou os custos de produção. Uma vez que a falta de produção congelou todos os outros setores da miniempresa, todos os resultados da miniempresa Ecopuff foram impactados, tanto de pessoal e organizacional quanto administrativo e de produção. 
A quantidade de pufes a serem produzidos e vendidos foi estabelecido pela Diretoria Financeira a partir da projeção financeira elaborada, objetivando-se encontrar o Ponto de Equilíbrio financeiro (PE). A projeção de produção para alcançar o PE era de 34 pufes, no entanto, a Ecopuff não conseguiu atingir o resultado mínimo projetado por meio do $\mathrm{PE}$, segundo as expectativas projetadas.

Foram estabelecidos o custo fixo e variável, Custo de Material Direto - CMD, entre outros dados essenciais, a partir de pesquisas de mercado. Definido o preço de venda inicial e já com produtos prontos para a comercialização, outros custos acessórios surgiram, elevando os custos e, consequentemente, o preço do produto. Entretanto, foi identificado uso exagerado (desperdício) de alguns insumos que aumentaram o custo unitário do produto, implicando no preço de venda inicial em $20 \%$ abaixo do custo real, gerando assim um prejuízo razoável, e muito comum até em grandes empresas.

Dessa forma, mesmo após a revisão do preço de venda dos pufes a $\mathrm{R} \$ 50,00$ a unidade, não foi possível alcançar o equilíbrio financeiro, mesmo tendo vendido todos os pufes produzidos. Apesar de conseguir excelentes resultados em termos de vendas, a Ecopuff não conseguiu resultados positivos quanto ao atendimento do mercado, pois não foi capaz de atender à demanda de produto solicitada pelo mercado por falta de matéria prima e por não ter planejado corretamente os custos de produção dos pufes. Esse impacto ocasionou o resultado negativo, apresentado nas Tabelas 1 e 2 .

Tabela 1 - Demonstrativo de Resultados do Exercício

\begin{tabular}{lll}
\hline \multicolumn{2}{c}{ DEMONSTRATIVO DE RESULTADOS } \\
D.R.E \\
\hline Receitas & Vendas & $\mathrm{R} \$ 1135,00$ \\
Despesas & Impostos (20\%) & $\mathrm{R} \$ 227,00$ \\
& Salário & $\mathrm{R} \$ 208,38$ \\
& Comissões & $\mathrm{R} \$-$ \\
& Encargos & $\mathrm{R} \$ 82,62$
\end{tabular}

\begin{aligned} & Fornecedores $\mathrm{R} \$ 885,55 \\ &$ Aluguel $\mathrm{R} \$ 15,00 \\ &$ Lucro Líquido $\mathrm{R} \$(283,55) \\ &$ Impostos (IR + CSLL) $\mathrm{R} \$ 148,08 \\ &$\hline Lucro Final $\mathrm{R} \$-431,63 \\ &$\hline\end{aligned}

Fonte: Relatórios da Empresa EcoPuff

Tabela 2 - Balanço Patrimonial

BALANÇO PATRIMONIAL

\begin{tabular}{llll}
\hline \multicolumn{2}{c}{ Ativo (R\$) } & \multicolumn{2}{c}{ Passivo (R\$) } \\
\hline Caixa & 700,00 & Fornecedores & 885,55 \\
Venda & 1135,00 & Impostos & 375,08 \\
Matéria Prima & 71,00 & Salários & 208,38 \\
Imobilizado & - & Encargos & 82,62 \\
Estoque & 150,00 & Comissões & - \\
Recebíveis & 135,00 & Aluguel & 15,00 \\
& & Patrimônio \\
& & líquido \\
& Capital Social & 1056,00 \\
& & Resultado do & $-431,63$ \\
& & Exercício & \\
\hline Total & 2191,00 & Total & 2191,00 \\
\hline
\end{tabular}

Fonte: Relatórios da Empresa EcoPuff

A análise detalhada das Tabelas $1 \mathrm{e}$ 2 indica que um reajuste inicial dos custos e a diminuição de custos de produção, apoiada principalmente na prática de cotar três ou mais orçamentos, na busca de diferentes fornecedores, na diminuição de desperdícios, na compra de maior quantidade de matérias-primas por lote, e no gerenciamento de pessoal, além da previsão e maior mobilização para captação de matérias-primas recicláveis, seria o ponto limiar entre um resultado financeiro positivo e o negativo.

Apesar dos resultados financeiros negativos, a experiência da Miniempresa pode ser considerada um grande sucesso em termos educacionais. Como programa institucional que visa o desenvolvimento de pessoas com ênfase em empreendedorismo, não há o pressuposto de que a empresa deveria apresentar saldo positivo, embora isso fosse desejável. Com a Ecopuff, os alunos e investidores tiveram um decréscimo de aproximadamente 6 reais em suas ações, conforme é visto no balanço patrimonial, algo em torno de $40 \%$. Apesar disso, as medidas adotadas, a forma de pensar, as dificuldades e os problemas resolvidos, proporcionaram aos estudantes a 
vivência de situações como empresários e empreendedores, o que pode ser considerado resultado positivo da implementação do Programa no ambiente educacional.

\section{A EXPERIÊNCIA E SUAS CONTRIBUIÇÕES PARA A FORMAÇÃO}

Buscou-se conhecer a percepção dos achievers sobre o Programa Miniempresa, os efeitos do Programa em sua vida e sugestões para futuras implementações do Programa. Os estudantes avaliaram o Miniempresa de forma positiva, ressaltando sua contribuição para características pessoais e profissionais para além do empreendedorismo.

Dos estudantes que responderam ao questionário, $93,3 \%$ concordam total ou parcialmente que o Programa Miniempresa é bom; apenas um estudante discordou parcialmente. $86,7 \%$ gostariam que o Miniempresa ou outro Programa semelhante continuasse ocorrendo no Ifes campus Itapina, sendo que o mesmo percentual indicaria o Programa Miniempresa para que um amigo ou familiar participasse futuramente. $80 \%$ concordaram total ou parcialmente que o Programa Miniempresa trouxe coisas boas para sua vida, e $66,7 \%$ do total de entrevistados acredita que a participação nas atividades do Programa alterou positivamente sua vida/rotina.

Todos os estudantes respondentes concordam total ou parcialmente que sua participação nas atividades do Programa Miniempresa os fez perceber a importância de planejar (100\% concorda totalmente), de ser organizado $(86,7 \%$ concorda totalmente e $13,3 \%$ parcialmente) e de buscar informações para embasar suas decisões $(73,3 \%$ concorda totalmente e $26,7 \%$ parcialmente). $86,7 \%$ desses estudantes concordam totalmente que o Programa fez perceber a importância de criar prioridades em sua vida $(6,7 \%$ concordam parcialmente e $6,7 \%$ não concordam nem discordam).
Os estudantes participantes, em sua totalidade, afirmaram ter feito novas amizades em função de sua participação no Programa, sendo que 93,3\% concorda total ou parcialmente que seu comprometimento com as coisas foi melhorado, assim como sua interação com outras pessoas, suas contribuições em trabalhos em grupo, sua vivência em equipe e seu senso de responsabilidade (este último com $86,7 \%$ de concordância). A capacidade de liderança dos estudantes também foi melhorada, de acordo com a percepção de $60 \%$ dos participantes. Destaca-se que $100 \%$ dos membros da Diretoria da Miniempresa Ecopuff afirmaram ter melhorado sua capacidade de liderança a partir de seu exercício no Programa, bem como 40\% dos não membros. Para 86,7\%, o Programa contribuiu para seus conhecimentos sobre empreendedorismo, enquanto apenas $46,7 \%$ passaram a ter mais vontade de ter seu próprio negócio futuramente.

Esses resultados foram obtidos a partir da resposta dos participantes a uma escala de 1 a 5, sendo 1 "discordo totalmente" e 5 "concordo totalmente" quanto às afirmativas apresentadas.

Apesar dessas percepções positivas, alguns alunos afirmaram que as mesmas ainda não refletiram em ações concretas de seu cotidiano, mas que irão procurar incluir esse aprendizado à sua realidade introduzindo as habilidades de gestão de empresa para seus desafios futuros. Além disso, foi evidenciado que a dedicação e motivação dos alunos individualmente (conforme sua autoavaliação) e do grupo como um todo poderia ser melhor.

A empresa EcoPuff foi organizada entre presidente, funcionários e diretoria, sendo esta última composta por cinco alunos, com a missão de dirigir, planejar, organizar e controlar as atividades dentro da empresa, fixando políticas de gestão dos recursos financeiros, administrativos, estruturação, racionalização e adequação dos diversos serviços gerados dentro do ambiente de trabalho. Cada diretor era 
responsável por uma área específica (Marketing, Produção, Finanças e Recursos Humanos). Para os alunos, é preciso envolver mais os funcionários para que desenvolvam habilidades gerenciais, sugerindo que haja rodízio de cargos.

Entre as críticas apontadas pelos participantes do Programa, destaca-se a desaprovação quanto aos horários dos encontros e a grande intensidade e duração das atividades das jornadas, durante as quais os estudantes demonstravam estar cansados. Outro ponto frisado pelos discentes $(33 \%)$ foi a dificuldade de coincidir as atividades do Programa com a disponibilidade de horários de ônibus no campus Itapina e principalmente o acúmulo de componentes curriculares da matriz curricular de seus cursos técnicos integrados ao ensino médio.

Essa percepção se deve principalmente ao fato de que o programa foi executado junto a alunos dos cursos Técnicos em Agropecuária e Zootecnia integrados ao Ensino Médio com grande carga horária curricular, desenvolvido durante 18 jornadas nas dependências do Campus Itapina após o horário destinado às atividades dos cursos regulares. Isso fez muitos desistirem por não conseguirem aliar a alta carga horária de estudo com a demanda da Miniempresa, principalmente na etapa de produção, na qual os alunos precisavam se dedicar mais às metas estabelecidas e ao cumprimento dos prazos.

As questões negativas apontadas pelos participantes evidenciam elementos cruciais para a permanência e êxito em cursos, inclusive regulares, como a melhoria de acesso, transporte e mobilidade ao campus e a diminuição da sobrecarga de atividades em cursos em período integral, destacando a importância de ações inter/multisciplinares e integradas aos conhecimentos básicos e técnico.

Sobre o conteúdo abordado ao longo do Programa, 20\% afirmou que esse poderia ser melhorado, sugerindo-se que aumente a carga horária teórica, apresentando mais exemplos de empreendedores e de como gerir um negócio no mercado atual, o que, segundo Leite e Fernandes (2002), é elemento importante no aprendizado, pois a educação empreendedora requer que os alunos tenham exposição substancial, coloquem a "mão na massa" e vejam na prática o mundo dos empreendedores, tendo experiências com empreendedorismo.

Dornelas (2014) corrobora esse argumento, ao afirmar que os empreendedores precisam ser visionários, ter a habilidade de implementar seus sonhos e tomar decisões na hora certa, e esse processo é feito quando há uma percepção de planejamento e de que se aprende fazendo, que é uma metodologia desenvolvida pelo programa. Transformam ideias abstratas de negócios em um produto concreto e possibilitando ao aluno agregar valor para a sociedade através de seus produtos sustentáveis.

\section{CONSIDERAÇÕES FINAIS}

Entre alunos e voluntários (achievers e advisors) envolvidos no Programa almejava-se uma miniempresa produtiva, com bons resultados financeiros, grande engajamento e excelente desempenho. Contudo, este não foi o resultado alcançado. A diferença entre a expectativa e a realidade é onde se encontra o empreendedor, que busca alcançar o que foi sonhado, mesmo com uma realidade dura.

O Programa Miniempresa trouxe aos estudantes do Ifes campus Itapina uma visão básica e explicativa de como é o funcionamento de uma empresa, tendo habilidades e conhecimento em finanças, além de aprenderem a importância do comprometimento, desenvolvimento e organização em equipe, criando e estimulando a capacidade de liderança na reflexão por parte dos achievers quanto a sua vocação e disponibilidade imediata para que enfrentem os desafios de empreender.

A metodologia utilizada pelo programa engaja os alunos (achievers) no processo de formação de uma empresa, 
desde sua idealização à fundação e funcionamento, do desenvolvimento do produto até a apuração de custos/lucros. Isso cooperou positivamente para o desenvolvimento e estimulação da capacidade empreendedora, visto que os participantes obtiveram uma nova visão sobre empreendedorismo, mesmo tendo a intenção de ingressarem no Ensino Superior em áreas diversas futuramente.

Apesar do alto índice de evasão de alunos em sua fase inicial, justificado como sendo devido à dificuldade de coincidir as aulas ministradas no projeto com a disponibilidade de horários e por não conseguirem aliar a alta carga horária de estudo dos Cursos Técnicos com a demanda da Miniempresa, o objetivo do Programa foi alcançado com sucesso, pois propôs reflexões, estimulou o empreendedorismo e incitou a prática administrativa em um cenário real, mas relativamente controlado.

Mesmo diante dos desafios, não se espera que todos os jovens o tenham como perspectiva de futuro para empreender um negócio e sim capacitar o cidadão a decisões perante a vida, como construção de identidades cativando um espírito de iniciativa, autonomia e criatividade, promover o seu desenvolvimento, sua aplicação prática no sentido de potenciar uma capacidade de encontrar soluções para problemas ou situações específicas.

Nesse sentido, o Programa Miniempresa foi fator preponderante para motivar, construir e ajudar a desenvolver habilidades essenciais ao que se faz necessário para o mercado de trabalho, e também construir uma nova relação com os recursos, alcançando os objetivos propostos durante as atividades. Seu maior legado, apontado com frequência pelos estudantes, foi de que o Programa contribuiu para a maior maturidade na percepção da importância de planejar e se organizar, que faz a experiência empreendedora ter valido a pena, pois na perspectiva de Dornelas (2014), mais importante que o conhecimento técnico, o empreendedorismo é compreendido como atitude. Em adição, a abordagem do empreendedorismo por meio do Programa Miniempresa no Ifes campus Itapina, para além de resultados financeiros e de produtividade empresarial, atuou como instrumento de aprendizado para a vida.

\section{REFERÊNCIAS}

AMORIM, D. A. A Pedagogia

Empreendedora na Educação Básica brasileira. Revista Científica

Multidisciplinar Núcleo do

Conhecimento. Ano 03, Ed. 03, Vol. 03, pp. 14-35, março de 2018.

\section{DOLABELA, F. Empreendedorismo:} uma forma de ser. Brasília: AED, 2003.

\section{DORNELAS, J.C.A. Empreendedorismo:} transformando ideias em negócios. 5. ed. Rio de Janeiro: Empreende / LTC, 2014.

Empreendedorismo corporativo.

Rio de Janeiro: Elsevier, 2009. 166p.

JUNIOR ACHIEVEMENT. Programas.

Disponível em: <http://www.jarn.org.br/ programas.php>. Acesso em: 24/03/2020.

\section{LEITE, C.; FERNANDES, P.}

Potencialidades e limites da gestão local do currículo para (e na) construção de uma escola com sentido para todos. In:

ME/DEB. Gestão flexível do currículo.

Reflexões de formadores e investigadores. Lisboa: DEB, 2002.

LIKERT, R. A technique for the measurement of attitudes. Archives of Psychology, 22(140), 1-55. 1932.

\section{LOPES, R.M.A. Educação}

empreendedora: conceitos, modelos e práticas. São Paulo: Elsevier, 2010.

SOUZA, E. C. L.; SOUZA, C.C.L.; ASSIS, S.A.G.; ZERBINI, T. Métodos e Técnicas de Ensino e Recursos Didáticos para o Ensino do Empreendedorismo em IES Brasileiras. In: EnANPAD 2004, 2004. Disponível em: <http://www.anpad.org.br/ 
admin/pdf/enanpad2004-epa-trabalho convidado.pdf >. Acesso em: 24/03/2020.
YIN, R.K. Estudo de Caso: planejamento e métodos. Porto Alegre: Bookman, 2015. 